\title{
POPQ EXAMINATION: DOES THE TIME OF EXAMINATION INTERFERE WITH POPQ MEASUREMENT SYSTEM FOR THE ASSESSMENT OF GENITAL PROLAPSE?
}

\author{
Madkar Chandrakant $S^{1}$, Deshpande Hemant $G^{2}$, Trivedi Yogesh $I^{3}$ \\ ${ }^{1}$ Professor, Department of Obstetrics \& Gynaecology, Dr. D. Y. Patil Medical College, Pune. \\ ${ }^{2}$ Professor and HOD, Department of Obstetrics \& Gynaecology, Dr. D. Y. Patil Medical College, Pune. \\ ${ }^{3}$ Chief Resident, Department of Obstetrics \& Gynaecology, Dr. D. Y. Patil Medical College, Pune.
}

\section{ABSTRACT}

$\overline{\text { AIM }}$

To testify the fact about generalised untested belief that genital prolapse is more severe in the late afternoon as compared to the morning with the help of POPQ classification system.

\section{METHOD}

There is a generalised belief that prolapse is more severe at the end of the day as compared to the morning. We have planned this study to know whether this belief is correct or wrong. It is not possible to do this study with the help of old classification. So we decided to do it with the help of new classification, that is POPQ system. This is prospective study undertaken with permission of ethical committee consisting 48 patients attending gynec OPD of Dr. D. Y. Patil Medical Hospital. Each patient was examined with POPQ system twice, i.e. two visits and two sessions per visit, morning 9 am to 10 am and late afternoon 4 pm to 5 pm, which are our OPD timings. She was again called after one week and re-examined by the same person twice in a day as mentioned above. Findings were noted in different files and at the end of study data was analysed by applying statistical test of significance.

\section{RESULTS}

The study consisted of 48 patients. The POPQ exam stages were $47 \%$ stage II, $50 \%$ stage III, and $3 \%$ stage IV. There was no significant difference for the 9 POPQ exam measures between morning and afternoon exams. There was good agreement between AM and PM POPQ ordinal stages (Weighted Kappa value 0.76).

\section{CONCLUSION}

There is no difference between AM and PM POPQ exam results.

\section{KEYWORDS}

POPQ System, Genital Prolapse, Time of Examination, ICS, AUGS.

HOW TO CITE THIS ARTICLE: Madkar Chandrakant S, Deshpande Hemant G, Trivedi Yogesh I. "PopQ Examination: Does the Time of Examination Interfere with PopQ Measurement System for the Assessment of Genital Prolapse?" Journal of Evolution of Medical and Dental Sciences 2015; Vol. 4, Issue 101, December 17; Page: 16694-16697, DOI: 10.14260/jemds/2015/2495

\section{INTRODUCTION}

Uterine prolapse is an ailment that has seemingly affected women for all of time. In fact the problem of uterine prolapse and its potential treatment is described in the oldest documented medical literature, the Egyptian papyri, where it is written, "Of a woman whose posterior, belly and branching of her thighs are painful, say thou as to it, it is the falling of the womb," (Kahun papyrus ca. 1835 B.C.E.).[1] The Ebers papyrus goes on to recommend "to correct a displaced womb: with oil of earth (Petroleum) with fedder (Manure) and honey; rub the body of the patient," (Ebers papyrus ca. 1550 B.C.E.).[2]

Prolapse refers to a downward displacement of the uterus, vaginal walls and surrounding structures like the bladder, bowel or rectum from their normal anatomical positions. In severe cases, the vaginal walls or cervix may protrude beyond the introitus and are visible or palpable outside the body.(3)

Financial or Other, Competing Interest: None.

Submission 21-11-2015, Peer Review 23-11-2015,

Acceptance 10-12-2015, Published 17-12-2015.

Corresponding Author:

Dr. Trivedi Yogesh I,

Dr. D. Y. Patil Boys Hostel,

Pimpri,

Pune-411018.

E-mail:yogesht88@yahoo.com

DOI:10.14260/jemds/2015/2495
Studies show that among the reproductive health problem faced by women, the most common problem is genital prolapse. Commonly women are keeping this condition secret because of the shame, as it is affecting a sensitive part. So it is considered as a "Hidden tragedy for women." (4)

According to 'WHO' estimation, the reproductive ill health accounts for $33 \%$ of the total disease burden in the woman globally. ${ }^{4}$ The global prevalence of uterine prolapse is 2-20\%. Internationally, according to Oxford Family Planning Association UK, the hospital admission for uterine prolapse is $20.4 \%$, surgery for prolapse is $16.2 \%{ }^{4}$ The incidence of uterine prolapse in U.S.A. is $11.4 \%$, Egypt $56 \%$, Italy $5.5 \%$, Iran $53.6 \%$, California $1.9 \%$ and Pakistan $19.1 \%$. It is estimated that more than 60,000 women in Nepal are suffering from uterine prolapse, out of which 18600 are in need of surgical repair.(4)

In India it is found that among women visiting private clinics in Bengal, Delhi, Punjab and Uttar Pradesh with gynecological problems, one in five are suffering from uterine prolapse. In Northern India the incidence of uterine prolapse is $7.6 \%$, Eastern India 20\%. In Southern India, Tamilnadu, the incidence of uterine prolapse is $0.7 \%$ and in Karnataka the incidence of uterine prolapse is $3.4 \% .(4,5)$

The most of classification of prolapse are based on criteria modified from Beechem and Baden et al.(6,7)

Pelvic organ prolapse quantification (POP-Q) describes specific sites on the vaginal wall for describing the anatomy of the patient's prolapse. These anatomical positions can then be used to determine the stage of prolapse. $(8,9)$ 
The POP-Q system uses a series of site specific measurements of the pelvic organ supports. Prolapse in each segment is measured relative to the hymen and not the introitus. Six points are located with reference to the plane of hymen, i.e. $\mathrm{Aa}, \mathrm{Ba}, \mathrm{C}, \mathrm{D}, \mathrm{Bp}, \mathrm{Ap}$. Other landmarks used are genital hiatus (gh), perineal body (pb), and total vaginal length (tvl).

- Point Aa: located in the midline of the anterior vaginal wall $3 \mathrm{~cm}$ proximal to the external urethral meatus.

- Point Ba: represents the most dependant position of any part of the upper anterior vaginal wall from anterior vaginal fornix to point Aa.

- Point C: a point that represents either the most distal (or the most dependant) part of the cervix or the leading edge of vaginal cuff after total hysterectomy.

- Point D: a point which represents the posterior fornix. It represents the level of attachment of uterosacral ligaments to the cervix. This point is omitted in the absence of cervix.

- Point Bp: represents the most dependant position of any part of the upper posterior vaginal wall from posterior vaginal fornix to the point Ap.

- Point Ap: located in the midline of the posterior vaginal wall $3 \mathrm{cms}$ proximal to the hymen.

- Genital hiatus (gh): measures from middle of external urethral meatus anteriorly to the midline of hymen posteriorly.

- Perineal body (pb): the perineal body is measured from the posterior margin of the genital hiatus to the midanal opening.

- Total vaginal length (tvl): It is the greatest depth of vagina with point $\mathrm{C}$ or $\mathrm{D}$ reduced to full normal position.

\section{Stages of Pelvic Organ Prolapse}

Stage 0: No prolapse is demonstrated; points $\mathrm{Aa}, \mathrm{Ba}, \mathrm{Ap}, \mathrm{Bp}$ are at $3 \mathrm{cms}$ and points $\mathrm{C}$ or D - (tvl-2cms).

Stage 1: Most distal portion of the prolapse is $-1 \mathrm{~cm}$ (Above the level of the hymen).

Stage 2: Most distal portion of the prolapse $-1 \mathrm{cms}$ but $+1 \mathrm{cms}$ (1 $\mathrm{cms}$ above or below the hymen).

Stage 3: Most distal portion of the prolapse $>+1$, but $<$ (tvl -2$)$ cms beyond the hymen; protrudes no further than $2 \mathrm{cms}$ less that of total vaginal length.

Stage 4: Complete eversion; most distal portion of the prolapse $+($ tvl -2$)$ cms

This method of classification provides an accurate, precise and objective assessment of pelvic organ prolapse and it can also be useful for description and comparison of prolapse in populations. (3)

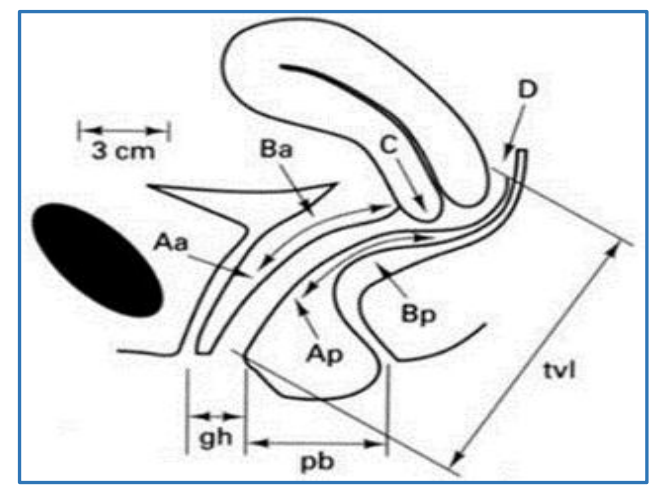

Fig. 1: Anatomical position of POPQ Components

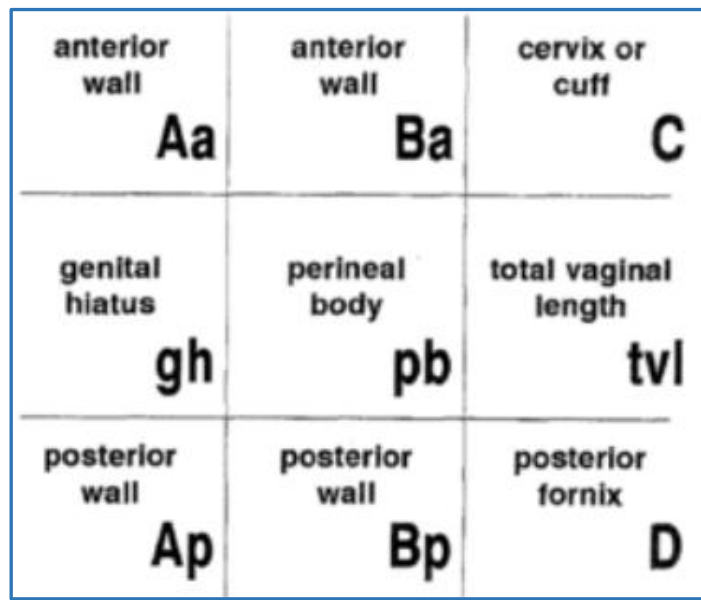

Fig. 2: Grids of POPQ Components

This Figure 1 explains different anatomical points taken into consideration.

Figure 2 explains grids of POPQ components.

Advantage of it (Such detailed information obtained by this system) is taken in our study, because this topic cannot be studied with the help of old classification.

\section{MATERIALS AND METHODS}

This study we specifically conducted to know whether there is change in the severity of prolapse in the early morning and late daytime, that is 9 to 10 am and 4 to $5 \mathrm{pm}$. For this sample of 48 patients qualifying inclusion criteria and coming to gynec OPD of Dr. D.Y. Patil Hospital were included.

This is prospective observational study in which permission of ethical committee was taken.

All subjects included in the study were provided a form for written consent including necessary details required for patient.

Patients were greater than 20 years of age, speak and understand Marathi/Hindi/English and also willing to come for examination as per schedule designed in our study. To have uniformity in the sample only housewives performing routine work (Uniform activity) were selected. Labour workers doing heavy work and office workers doing only sitting jobs were excluded.

Our patients were having regular activity in between two examination timings, which included cooking, washing, sitting and walking.

Following informed consent, the subjects asked to empty their bladder for undergoing examination by using standard POPQ technique in the dorsal lithotomy position, while performing a valsalva or cough.

Each patient was examined twice in a day at the timing of 9 am to 10 am and 4 pm to $5 \mathrm{pm}$, which were our OPD schedule timings. Findings were recorded in the group of file no. 1. Same patients were called after one week with same schedule of examination recorded in file no. 2 of follow-up group. Precaution was taken that the examination will be done by the same senior consultant without seeing file no. 1, findings to avoid person to person variation and bias. At the time of both examinations, patient was asked about the increase in severity of the symptoms like dragging pain, backache, etc.

Currently, pelvic organ prolapse was measured using the POPQ as described below.

There are three reference points anteriorly (Aa, Ba and C) and three posteriorly (Ap, Bp and D). Points Aa and Ap are $3 \mathrm{~cm}$ proximal to or above the hymenal ring anteriorly and 
posteriorly respectively. Points $\mathrm{Ba}$ and $\mathrm{Bp}$ are defined as lowest points of prolapse between Aa anteriorly or Ap posteriorly and the vaginal apex. Anteriorly, the apex is point $\mathrm{C}$ (Cervix) and posteriorly is point D (Pouch of Douglas). In women after hysterectomy, point $\mathrm{C}$ is the vaginal cuff and point $\mathrm{D}$ is omitted. Three other measurements are taken: the vaginal length at rest, the genital hiatus (gh) from the middle of the urethral meatus to the posterior hymenal ring and the perineal body $(\mathrm{pb})$ from the posterior aspect of the genital hiatus to the midanal opening.

As normality was not assured in the continuous data in this trial, nonparametric statistics were utilized and central location presented as median and interquartile range. Differences in POPQ individual measurement points between exams were tested with Wilcoxon Signed rank for paired data. Finally, agreement between am and pm examination POPQ stage was performed with the weighted Kappa statistics. The value of Kappa defines the strength of agreement as fair $(\mathrm{k}=0.21-0.40)$, moderate $(\mathrm{k}=0.41-0.60)$, good $(\mathrm{k}=0.61-0.80)$ and very good $(\mathrm{k}=0.81-1 \cdot 00)$. All analyses were performed with MedCalc version 15.10.0 (64bit) \& WinPEPI software for statistical calculation.

More than $1 \mathrm{~cm}$ difference between $\mathrm{AM}$ and $\mathrm{PM}$ measurements was selected as a clinically significant difference that would favors a preference in timing of $P O P Q$ exam. The sample size was 48 pairs of patients (48 patients with morning and afternoon measurement).

\section{RESULTS}

\begin{tabular}{|c|c|}
\hline Demographic & (Median IQR) \\
\hline Age & $53(43-62)$ \\
\hline BMI & $25.2(22.6-28.1)$ \\
\hline & \\
\hline Gravidity & Patients (\%) \\
\hline 0 & $2(4 \%)$ \\
\hline 1 & $3(6 \%)$ \\
\hline$>2$ & $43(90 \%)$ \\
\hline \multicolumn{2}{|c|}{ Table 1: Demographic details of the patients } \\
\hline
\end{tabular}

\begin{tabular}{|c|c|c|c|}
\hline Symptoms & $\begin{array}{c}\text { Increased } \\
\text { Dragging Pain }\end{array}$ & $\begin{array}{c}\text { Increased } \\
\text { Backache }\end{array}$ & Both \\
\hline $\begin{array}{c}\text { No. of } \\
\text { patients }\end{array}$ & $19(08)$ & $24(13)$ & 11 \\
\hline $\begin{array}{c}\text { Percentages } \\
(\%)\end{array}$ & $44 \%$ & $56 \%$ & $25 \%$ \\
\hline
\end{tabular}

Table 2: Symptomology (Out of 48 patients, 43 patients has changed in severity of symptoms)

About symptomatology, there was change in severity of the symptoms as shown in the Table 2 . Increase in dragging pain $44 \%$, backache $56 \%$ and both symptoms $25 \%$.

\begin{tabular}{|c|c|c|c|}
\hline Measurement & $\begin{array}{c}\text { AM } \\
\text { Measurement }\end{array}$ & $\begin{array}{c}\text { PM } \\
\text { Measurement }\end{array}$ & $\begin{array}{c}\text { P } \\
\text { value* }\end{array}$ \\
\hline $\mathrm{Aa}$ & $0.0(-2.0,2.0)$ & $0(-2.0,2.0)$ & 0.39 \\
\hline $\mathrm{Ba}$ & $1.0(-2.0,3.0)$ & $1.0(-2.0,3.0)$ & 0.28 \\
\hline $\mathrm{C}$ & $-5.0(-7.0,-3.0)$ & $-6.0(-7.0,-2.0)$ & 0.74 \\
\hline $\mathrm{Gh}$ & $4.0(3.0,5.0)$ & $4.0(3.0,5.0)$ & 0.30 \\
\hline $\mathrm{Pb}$ & $3.0(2.0,3.0)$ & $3.0(2.0,3.0)$ & 0.28 \\
\hline $\mathrm{TVL}$ & $7.0(6.0,8.0)$ & $7.0(6.0,8.0)$ & 1 \\
\hline $\mathrm{Ap}$ & $-1.0(-2.0,0.0)$ & $-1.0(-2.0,0.0)$ & 0.38 \\
\hline $\mathrm{Bp}$ & $-0.5(-2.0,0.0)$ & $-1.0(-2.0,0.0)$ & 0.39 \\
\hline $\mathrm{D}$ & $-6.0(-8.0,-5.0)$ & $-6.0(-7.0,-5.0)$ & 1 \\
\hline
\end{tabular}

Table 3: Difference between Morning and Afternoon individual POPQ measurements

(Median/Interquartile range)

${ }^{*} \mathrm{P}$ value (Wilcoxon signed rank) ( $\mathrm{p}$ value $<0.05$ is significant).
Result shows that there is no statistical significant value of AM measurement and PM measurement in individual POPQ components. At each individual POPQ point of measurement, there was no significant difference between $\mathrm{AM}$ and PM exams (all P values <.05) (Table 3).

\begin{tabular}{|c|c|c|c|}
\hline $\begin{array}{c}\text { POPQ STAGE } \\
\text { AM } \\
\end{array}$ & & $\begin{array}{c}\text { POPQ STAGE } \\
\text { PM } \\
\end{array}$ & \\
\hline & II & III & IV \\
\hline II & $20 / 48(41 \%)$ & $3 / 48(6 \%)$ & 0 \\
\hline III & $3 / 48(6 \%)$ & $21 / 48(44 \%)$ & 0 \\
\hline IV & 0 & 0 & $\begin{array}{l}1 / 48 \\
(3 \%)\end{array}$ \\
\hline
\end{tabular}

Weighted Kappa value: 0.76 (95\% CL $0.54,0.98)$ Excellent agreement 48 sequential subjects met inclusion criteria and completed both morning and afternoon POPQ testing. At both $\mathrm{AM}$ and PM examinations, $41 \%$ were stage II $(n=20), 44 \%$ stage III $(n=21)$ and $3 \%$ stage IV $(n=1)$ (Table 4$)$.

Result shows that there is no statistical significant value of difference between $\mathrm{AM}$ and $\mathrm{PM}$ in POPQ stages. For individual POPQ stage, a total of $12 \%(n=6)$ subjects had discordant POPQ stages between AM and PM measurement. Of the $12 \%, 3(50 \%)$ increased stage from II to III in going from a morning to an afternoon exam and $3(50 \%)$ decreased their stage from III to II going from morning to an afternoon (Table 4). In this sample, there is excellent agreement between $A M$ and PM POPQ stage weighted kappa $=0.76$ (95\% CI 0.54, 0.98).

The importance of our study is in the fact that if we get significant difference between $\mathrm{AM}$ and PM timings, then patient will be required to come for checking at specific time when the figures are expected to be on higher side. It can cause lot of inconvenience to the patient. However, our study shows no significant statistical difference, so this problem does not arise and patient can be called anytime to the OPD according to her convenience.

The results of this study would suggest that there is no substantial difference between exams done early in the day vs. late in the evening. It should be noted that for all of the POPQ points measured there was not more than $1 \mathrm{~cm}$ difference between morning and afternoon results (Table 4).

When noting differences in POPQ ordinal stage between morning and afternoon exams, there were 3 patients that showed change in the stages (Stage II to a stage III) between morning and evening and 3 patients changes stages (Stage III to a stage II) between morning and afternoon.

About symptomatology, there was change in severity of the symptoms as shown in Table 2. At the end of the day, there is increase in dragging pain $44 \%$ and backache $55 \%$, both $25 \%$ (Table 2), which can be due to increase in gravity force while doing routine activity in standing or walking position.

One important feature of this study is that the same examiner did both exams. This means that the study is not blinded.

To achieve the statistical figures, we assume that a clinically significant difference in the individual POPQ exam points is a difference of greater than $1 \mathrm{~cm}$, as $1 \mathrm{~cm}$ or less difference in a POPQ point is unlikely to alter clinical management.

\section{DISCUSSION}

Our basic purpose of this study is to test the general understanding that at the end of day there is increase in the status of genital prolapse. This belief was probably formed on the basis of increase in severity of the symptoms at the end of day than in morning, which is also seen in our study (Table 3). This might be due to natural force of gravity physical activity and various other causes of increased intra-abdominal pressure throughout the day. This understanding is myth 
because nobody has tested about the fact of increase prolapse at the end of day. The main reason for this lacunae was unavailability of proper classification prior to 1996, which was inaccurate imprecise vague and misleading. So it was not possible for the consultant, which will enable them to get the required statistical figures. There was little agreement in defining POP parameters in old classification, but in 1996 Bump et al.(9) described POPQ system which was completely studied and scrutinized in detail and then only it was adopted by ICS and AUGS.

This classification was practically overcoming all the difficulties to obtain the required statistical figures, because it was accurate and precise giving clear-cut measurement useful for statistician and academician. As quoted by Paul Riss, it represented breakthrough invention.(10) That is why this system becomes very popular and useful as shown by (Treszezcion et al.). 'Use of POPQ was significantly increased in all subgroups showing POPQ is being adopted as the universal language published literature."(11)

This simple problem remained untested for a long time and after going through literature in detail we were able to get only one study done by Melissa Pearce et al. (AJOG).(12) This research was also presented and well appreciated at the $70^{\text {th }}$ annual meeting in South Atlantic Association of OBGY. The results of their study indicate that there was no significant difference between the findings of morning and afternoon examination at each individual POPQ point of measurement according to POPQ system. Our study is also showing the same results and we fully agree with their opinion and conclusion. This study statistically proves that stages of prolapse do not change with the time of the day. There is no difference in results between $\mathrm{AM}$ and $\mathrm{PM}$ in POPQ stages.

\section{CONCLUSION}

The results of this study suggest that for patients complaining of uterovaginal prolapse with the leading edge of their vaginal walls extending beyond the hymen, there is no need to repeat an exam late in the day to document the full extent of their pelvic organ prolapse. It is probably more important to have the patient confirm their prolapse during exam.

Study proves that the time of the day does not influence the overall POPQ stages rather than evaluation may be performed at the convenience of evaluator or the subject.
We think that more studies with large samples should be done on this problem.

We positively hope that many such unknown and untested beliefs can be tested in the light of POPQ staging system, which will help in diagnosing and managing the POP patients.

\section{REFERENCES}

1. McKay WJS. The History of Ancient Gynaecology, Balliere, Tindal and Cox, London, UK, 1901.

2. Bryan CP. Ancient Egyptian medicine: The Papyrus Ebers, Ares Publishers, Chicago, Ill, USA, 1974.

3. Pandit SN, Akolekar R. Pelvic organ prolapse for FOGSI, National book depot, 2009; Introduction;ch01;p01; Pelvic Organ Prolapse;ch03;p18.

4. Anata Raj Bajracharya. Uterine prolapse: A Hidden Tragedy for women [Online]. [2007 Nov 23]; Available from: URL: http://www.Shvoong.com/medicine and health/gynaeology/1711392-Uterine prolopse hiddentragedy-Women.

5. Anjum Doshani, Roderick EC Teo, Christopherj Mayne, et al. Uterine Prolapse-Clinical Review. BMJ 2007;335:819-823.

6. Baden WF, Walker T. Fundamentals, symptoms and classification. In: Baden WF, Walker T, eds. Surgical repair of vaginal defects. Philadelphia, PA: JB Lippincott; 1992:14

7. Beecham CT: Classification of vaginal relaxation. Am J Ostet Gynecol 1980;136:957.

8. Walters MD: Description and classification of pelvic organ prolapse: Urogynecology and reconstructive pelvic surgery. $2^{\text {nd }}$ Ed. Mosy 1999.

9. Bump RC, Mattasson A, Bo K, et al. The standardization of terminology of female pelvic organ prolapse and pelvic floor dysfunction. Am J Ostat Gynecol 175:10, 1996.

10. Paul Riss, Dwayer PL. The POP-Q Classification system: looking back and looking forward; Int Urogynecol J 2014;25:439-440.

11. Treszezciansky AD, Racoff L, Vandy MD, et al. Use of POP staging system in published articles of selected specialised journals Int Urogynecol; 03;2010;21;3;359-363.

12. Melissa Pearce, Steven Swift, Goodnight W. Pelvic organ prolapse: is there a difference in POPQ exam results based on time of day, morning or afternoon? American Journal of Obstetrics and gynecology 2008; Vol-199: 76-77. 